\title{
Research on Social Responsibility Reconstruction of Internet Media under the Major Emergencies
}

\author{
Maohua $\mathrm{Li}^{*}$ \\ Institute for Corporate Social Responsibility, Xi'an Siyuan University, Xi’ an, 710038
}

\begin{abstract}
The fulfillment of corporate social responsibility (CSR) is an engineering system, and all the parts of the system form a new social responsibility model. This paper systematically constructs a new social responsibility model under the major emergencies. The new model contains the inner layer and the outer layer. The inner layer is the driving force of the model, and the outer layer is the implementation part of the model. The inner layer drives the outer layer, and the outer layer takes a series of concrete measures under the action of the inner layer. At the end of the social responsibility cycle, a new social responsibility cycle will be started because of the change of the inner layer. "emergency in left-hand" and "responsibility in right-hand" is an eternal topic.
\end{abstract}

\section{Introduction}

Since the outbreak of COVID-19, it has been rampant in China, and all provinces in China have initiated the firstclass response mode. During the period of COVID-19, internet media played a significant role in transmitting information, guiding public opinion, and appeasing the people. Internet media's influence in COVID-19 surpasses traditional media because of its fast dissemination speed, wide dissemination of information, and timely interaction. As an emerging industry in recent years, internet media plays a significant role. Internet media should objectively report the real news, correct many incorrect statements that are easy to create panic on the internet and create a harmonious network environment.

\section{Literature review}

Zheng Haiping and Wang Lijie of Xi'an Foreign Studies University[1], through interviews and questionnaires, conducted an empirical survey on the current situation of private enterprises CSR performance in Shaanxi Province. And they analyzed the problems existing in the performance of corporate social responsibility, and put forward countermeasures in four aspects, such as strengthening the quality of private entrepreneurs. Zhang Caili[2] of Xi'an Fanyi University believes that the development of Shaanxi enterprises should conform to social ethics, realize the sustainable development of human beings, and connect with the labor movement and human rights movement. Huang Hongchao et al.[3], taking Shaanxi Mobile as an example, found that "many managers have a misunderstanding about corporate responsibility. They think that corporate responsibility is to create profits and be responsible to shareholders, which is a narrow concept of corporate responsibility." Li Maohua [4] of Xi'an Siyuan University believes that under the COVID19 situation, survival responsibility is the first responsibility of the enterprises. And Maohua Li constructs the social responsibility model of Xi'an enterprises based on survival responsibility.

\section{Theoretical basis of reconstruction}

\subsection{Maslow's hierarchy of needs}

Maslow [5] believes that human needs are composed of five hierarchies: "physiological", "safety", "belonging and love", "social needs or esteem", and "self-actualization" needs. This theory also applies to business organizations. The needs for an enterprise in social development are also hierarchical, and the level of these needs increases with the enterprise life cycle.

\subsection{Corporate sociality theory}

Sociality is the expression of the consciousness of social animals, which makes the survival ability of individuals within society far exceed that of individuals separated from society[6]. Sociality mainly includes such characteristics as altruism, cooperation, dependence, and higher consciousness. Sociality is a proper term in Biology, however, with the complexity of the social division of labor, the structure of a social system, and the close relationship of cooperation, enterprise organizations also show more and more social characteristics.

\subsection{Business ecosystem}

* Corresponding author: maohua.li@qq.com 
The business ecosystem is an economic community based on interacting organizations and individuals that, over time, jointly develop their capabilities and roles and tend to develop themselves in the direction of one or more central enterprises.

In short, business ecosystems include enterprises themselves and their customers, market media (including agents, people who provide business channels and sell complementary products and services), suppliers, and these can be considered as primary species of business ecosystems. Besides, a business ecosystem includes owners and controllers of these primary species (including government agencies and regulatory agencies, associations and standards representing consumers and suppliers).

\section{Reconstruction methodology}

System dynamics (SD) is an approach to understanding the nonlinear behavior of complex systems over time using stocks, flows, internal feedback loops, table functions, and time delay ${ }^{1}$.

System dynamics (SD) appeared in 1956 and was created by Professor Forrest of the Massachusetts Institute of Technology (MIT) in the United States. System dynamics is a system simulation method proposed by Professor Forrest in 1958 to analyze enterprise problems such as production management and inventory management. It is a subject of analyzing and studying information feedback systems, and also an interdisciplinary subject of understanding and solving system problems. In terms of system methodology, system dynamics is the unity of structural, functional, and historical methods. Based on system theory, it absorbs the essence of cybernetics and information theory and is a horizontal subject that integrates natural science and social science.

System dynamics (system dynamics) uses the system scientific thinking of "every system must have structure, and every system structure determines system function". According to the feedback of mutual causality among the internal components of the system, the inner layer of the system is used to find the root of the problem.

\section{Reconstruction of "Five-in-one" social responsibility model}

\subsection{System composition analysis}

Based on the theoretical research, COVID-19 situation analysis, typical experience research at home and abroad, and the actual situation analysis of major emergencies, this paper puts forward the "five-in-one" social responsibility model for major emergencies, as shown in Figure 1.

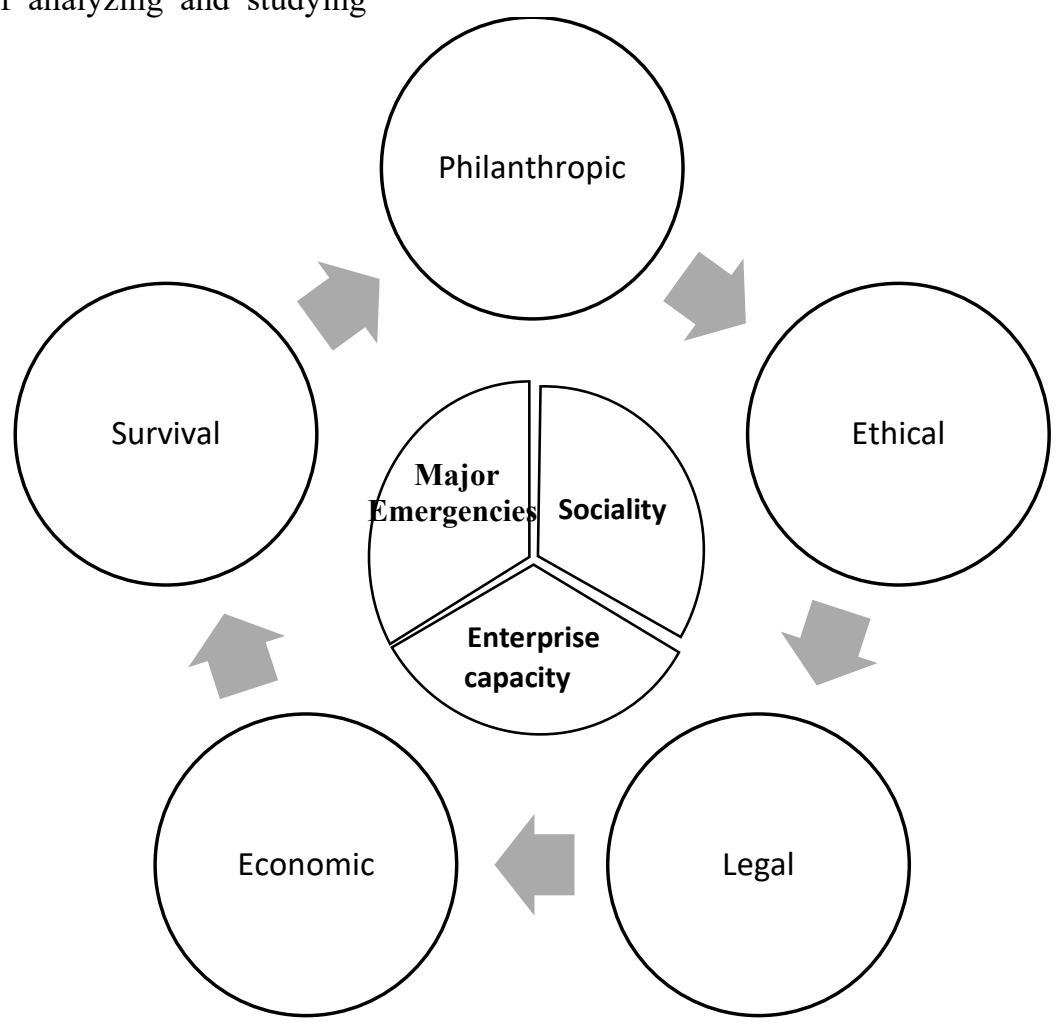

Fig. 1. The five-in-one model of social responsibility

\footnotetext{
1 Sourcing: https://web.mit.edu/sysdyn/sd-intro/
} 


\subsection{System dynamics analysis}

As shown in Figure 1, the "five-in-one" social responsibility model consists of two layers: the inner layer and the outer layer. The inner layer is the driving force part of the "five-in-one" model, which provides the internal power for the implementation of the whole CSR model. The outer layer consists of the different types of social responsibilities of Internet media under major emergencies, and these CSR types come from the CSR "gem model " by Maohua Li(2020). The outer layer consists of all kinds of social responsibilities which should be taken by the enterprise, and they are the results of the power from the inner layer.

The inner layer of the system is the power, and major emergencies consist a variety of social and natural events that have a significant economic and social impact on CSR, such as COVID-19. Major emergencies will force enterprises to make strategic decisions to change management, and CSR strategy should be a common decision for enterprises to tide over difficulties. Sociality is the role of enterprises in the social division of labor and industrial chain. It is a characteristic of survival and sustainable development in interaction with other social organizations. The sociality requires that enterprises should not only care about their interests and ignore the interests of other organizations and individuals in the industrial chain and social organizations, and sociality makes the assumption of social responsibility inevitable. Enterprise ability is the basis for determining the type and amount of corporate social responsibility. In the phase of enterprise establishment, the primary responsibility of the enterprise is to survive. With the growth of the enterprise, there are more and more types of social responsibility.

In the outer layer of system, there are five types of social responsibilities driven by major emergencies, sociality, and enterprise ability, and these five types of CSR are from the "gem model" by Maohua Li. These five points show the five aspects of social responsibility under major emergencies. CSR can be driven by a certain force, and CSR can be driven by three aspects of the force too. After each social responsibility is realized, with the change of enterprise and external environment, the new technology and the occurrence of major emergencies will make the enterprise enter the next link of social responsibility. So the model is a circular process, and corporate social responsibility can not be going to succeed overnight.

Survival is the priority of the enterprise, which has been proved by the current situation analysis. And this paper takes the catering industry as an example. This COVID-19 is also a survival challenge and transformation opportunity for Shaanxi catering industries. The recovery plan by Shaanxi Government should be carried out, and it is possible that the original business structure also needs to be adjusted. As a popular shop "Wenyi Bistro" in Shaanxi closed down, then resumed business and took out to make up for the loss and ensure survival. Take Muslim Street of $\mathrm{Xi}$ 'an as an example, the average daily customer flow on non-holiday days is 100000 , and the average daily customer flow on holidays is close to 300000 . Affected by COVID-19, the noisy Muslim Street is suddenly quiet, without the bustling crowd, the call of merchants, and the airless variety of food mixed with fireworks.

Legal responsibility requires Internet media to obey the national laws and regulations for production and operation even in the face of major emergencies. When the COVID19 situation is serious and the enterprise is required to stop work, the enterprise must make an immediate decision. " COVID-19 is an order" and enterprise must stop work and stop production. When the sustainability of social life requires enterprises to resume production, enterprises should not be afraid to resume production and should put COVID-19 prevention and control together.

Economic responsibility requires Internet media to produce as many economic benefits as possible under the premise of ensuring the survival of Internet media and the prevention and control of COVID-19 and to make their due contribution to the economic development of Shaanxi and the economic recovery of Shaanxi.

Ethical responsibility requires Shaanxi Internet media, even in the face of COVID-19, to hold their bottom line of business ethics, should not produce fake and inferior news.

Charitable responsibility requires Shaanxi Internet media to respond positively to the national call based on survival and make their due contribution to COVID-19 prevention and control. Internet media should contribute their own scientific and technological strength and productive capacity to fight COVID-19 based on their capabilities and make donations and personnel support for key areas of COVID-19 prevention.

\section{Development ways and countermeasures of the "Five-in-one" social responsibility model}

From the previous analysis of the COVID-19 current situation, concept reconstruction, governance system, and so on, it can be seen that Shaanxi Internet media, based on survival, must act from the perspective of win-win cooperation, improvement of their bargaining power, and strengthening government supervision, to better fulfill the social responsibility, to resist a major public health emergency such as COVID-19.

\subsection{Cooperation among Shaanxi internet media for a win-win result}

Both the theoretical model of game theory and the result of numerical simulation can be seen that only the social responsibility realization mechanism of Shaanxi Internet media based on cooperation is the best choice. It can make Shaanxi Internet media pay the minimum cost in the face of major emergencies and realize the social responsibility of Internet media in the best way. Then this cooperative game needs certain conditions to be realized, which include not only the relationship between Shaanxi Internet media, trading volume, and bargaining power but also the supervision of government administrative organs. 


\subsection{Government and market regulators should take the initiative}

In this COVID-19, life security products are the core resources related to the national economy, people's livelihood, and the normal and stable development of the national economy. Therefore, for the price of life support products, "the relevant departments are prepared early so that the price of life support products is always within a reasonable range". However, "the reform and perfection of life support products policy should adhere to the direction of marketization and give full play to the function of life support products futures market". Based on giving play to the role of the market, let the Internet media of life support products decide the cooperative relationship according to the supply and demand of the market. On the premise that the market plays a role, the government and the market supervision department can promote the persistence of the Internet media cooperation relationship of the life support products, and then help the life support products enterprises to better fulfill the social responsibility of the Internet media.

\subsection{The CSR model of Internet media should be reconstructed}

As a sudden "black swan event", this COVID-19 tells us that the social responsibility of Internet media is not a fixed concept, it will develop with the development of society. With the development of emergency or society, the connotation and extension of social responsibility will change and be reconstructed. This COVID-19 tells us that for enterprises, survival responsibility is also the responsibility of enterprises to society. An enterprise can survive COVID-19 and then keep its employees' jobs, which has made great contributions to the country and society.

\subsection{Social Responsibility of Internet Media Reorganizing from Multiple Aspects}

The COVID-19 has told Shaanxi enterprises that emergencies, survival pressure, social responsibility, and so on will become the "new normal". Under the pressure of emergency and survival, Shaanxi enterprises need to reconstruct the social responsibility of Internet media in many aspects while improving their ability to resist risks. This reconstruction includes the reconstruction of social responsibility strategy, the reconstruction of social responsibility realization mechanism, the reconstruction of social responsibility constitution, and the reconstruction of the ability to fulfill social responsibility.

\section{Conclusions and discussions}

Through the analysis of concept and theory, the influence analysis of major emergencies, and the actual situation of Shaanxi Internet media, this paper constructs the social responsibility model of Shaanxi Internet media. Through the study, the following conclusions are drawn:
Firstly, the Shaanxi Internet media social responsibility model is a systematic project. This system factory requires the Internet media to construct a social responsibility model suitable for their enterprises based on comprehensive analysis and study of the impact of major emergencies and the situation of enterprises themselves. This model is an organism composed of a series of specific measures.

Secondly, the Internet media CSR model of each part is closely related. Therefore, Shaanxi Internet media should pay close attention to public emergencies, find out the real reasons that affect the development of Shaanxi Internet media, and lay the foundation for better implementation of social responsibility.

Thirdly, the inner layer is the internal driving force that causes Shaanxi Internet media to assume social responsibility. This driving force of the inner layer may be the occurrence of major emergencies, the innovation of standard enterprises, and the change of Internet media itself. One of the changes or comprehensive changes will promote Shaanxi Internet media to take measures for the next step to assume social responsibility.

This work is sponsored by the research project of Shaanxi Social Science Fund: "Research on the Social Responsibility of Shaanxi internet media under Major Emergencies", Project No.: 2020R040

\section{References}

1. Haiping Zheng, Lijie Wang. Research on the Current Situation and Countermeasures of Social Responsibility Performance of Private Enterprises in Shaanxi Province[J]. Enterprise Economy, 2009(03):136-138.

2. Caili Zhang.Study on how Shaanxi Enterprises Implement Social Responsibility Standards[J]. Modern Enterprise,2014(04):19-20.

3. Hongchao Huang et al. Shaanxi Mobile Builds a New Model of Corporate Social Responsibility Practice[J]. C-Enterprise Management,2017(04):37-41.

4. Maohua Li. Research on the Realization Mechanism of Social Responsibility of Agricultural Products Processing Industry Based on Game Theory[J].Hubei Agricultural Sciences,2020,59(19):199-203.

5. Maslow, Abraham Harold. Religions, values, and peak experiences. Columbus: Ohio State University Press, 1964.

6. Wittel, Andreas. Toward a network sociality. Theory, culture \& society, 2001, 18.6: 51-76. 